\title{
Reduction Activity in Sprouts in Salt Stress Conditions and Definition of the Accumulation Dynamics of Photosynthetic Pigments
}

\author{
S. M. Abduyeva-lsmailova , N. A. Gasimov
}

Baku State University

\begin{abstract}
The reduction activity was determined by colourimetric method on the 7-day etiolated wheat and pea sprouts' roots and trunks that had been kept in salt stress $(0.05 \mathrm{M} ; 0.1 \mathrm{M}$ and $0.2 \mathrm{M} \mathrm{NaCl}$ ) conditions and directly affected by salt. Changes in the nature of the reduction activity was adequate for the whole experiment options with the effects of salt; a linear decrease of reduction activity was observed with the increasing concentration of salt solution. The only difference between the two options has been quantum. Taking into account the reduction activity's relation to the photosynthetic activity, in experiments changes of general amount of photosynthetic pigments in green seedlings under the effect of salt and the potential reduction of the root system according to the relations of donor-acceptor were also defined. The gained results show that 6-8 hours continuous lighting allows to enough accumulation of photosynthetic pigments and the amount of the reduction substances evicted to the root reaches a maximum with linear increase. While the low concentration of salt solution in wheat seedlings accelerates the synthesis of pigments with stimulating effect, this process is delayed in a high concentration; and saturation state for the pigments compared to the control system ( 8 hours) occurs more often ( 6 hours). The amount of the pigments and reduction potential of roots in pea seedlings on the whole experiments was lower than the control.
\end{abstract}

Keywords: sprout, reduction activity, 2.6-DXFIF, optical density, instant salinization, amount of photosynthetic pigments

The biological oxidation is very closely connected with the mineral nutrition of plants and therefore, feeding regime change is caused to plants' reduction activity change [Abduyeva, 2003]. The reduction activity defines the direction of all endergonic processes and its determination can be considered as one of the most important integral indicators of metabolism in extreme conditions. On the other hand, the reduction activity plays a crucial role for the regulation of non-enzymatic oxidation reactions in living organisms. So that, antioxidant system preventing these reactions in living organisms shows its antioxidant effect in reduction situation only and because of the activity loss after the oxidation, direct correlation between antioxidant of cell and reduction activity is set [Касумов, 2012].

\section{Objects and methods of the research}

The experiments were carried out with colourimetric method using devices like photocolourimeter (FEKM), compensation scheme (IRN-64), micro compressor (MK-2) and a recording device (galvanometer, potentiometer-KSP-4) [Касумов et all., 1976]. 2.6- dihlorfenolindofenol (2.6-DXFIF) was taken as a reduction indicator. Quite high $(+0.217 \mathrm{~V})$ reduction potential of this colouring is also favorable for discovering the reduction components with lower positive potential which has a considerable amount in homogenate.

As an object of study, soaked wheat and pea seeds in an ordinary tap water (control) and as a stress factor $\mathrm{NaCl}$ salt concentration of $0.05 ; 0.1$ and $0.2 \mathrm{M}$ solutions (experimental options) were used. The definition of the reduction activity was carried out on the sprouted seedlings in 7 days etiolated and natural scattered lighting conditions and the determination of the accumulation dynamics of photosynthetic pigments were within 12 hours for every 2 hours in green seedlings only. The enlightenment was $500 \mathrm{LK}$ and has been defined with the help of lux meter type of YU-116.

Because of the $0.2 \mathrm{M} \mathrm{NaCl}$ stress concentration,

This article is published under the terms of the Creative Commons Attribution License 4.0 Author(s) retain the copyright of this article. Publication rights with Alkhaer Publications.

Published at: http://www.ijsciences.com/pub/issue/2015-12/

DOI: 10.18483/ijSci.891; Online ISSN: 2305-3925; Print ISSN: 2410-4477 
other - higher concentrations of salt solutions had not been used [Gasimov, 2008].

During the experiments, seedlings grown in an ordinary tap water had been under the direct influence of salt on the appointment of reduction activity. The main goal in the experiments conducted with the instant salinization of the environment (as a model system) is to learn the effect of salt to the impact on the course of biochemical reactions not to plants in model systems. In this case, the effect of salt can be instantly found.

Direct salt adding in the environment of 7-day seedlings was carried out with concentrate solution acquisition of $0.05 \mathrm{M} ; 0.1 \mathrm{M}$; and $0.2 \mathrm{M}$. For this purpose, at the determination time of the reduction activity of 2.6-DXFIF, to the filtrate made from root and trunk sprouts of seedlings $2.9 \mathrm{mg}(0.05 \mathrm{M}) ; 5.850$ $\mathrm{mg}(0.1 \mathrm{M})$ and $11.7 \mathrm{mg}(0.2 \mathrm{M}) \mathrm{NaCl}$ were added and solving was carried out after 10 minutes.

Implanting seeds were carried out on the thermostat at $25^{\circ} \mathrm{C}$. Nearly isometric seedlings have been chosen to prepare the filtrate and $1 \mathrm{~g}$ was taken from each root and trunk sections after drying with filter paper and $5 \mathrm{ml}$ of distilled water was added, crushed in a mortar. Homogenate was filtered several times and the gained filtrate shed to two milliliters tub of photoelectrocolourimeter. Registration of optical density change in filtrate defined in every 3 minutes and carried out at $\mathrm{pH} 7$ and room temperature, neutral light filter of $70 \%$. During the measurement of the optical density of the studied homogenate by the addition of $0.05 \mathrm{ml}$ colouring to bathtub blended without stopping. Blending was carried out through electromagnetic system microcompressor MK-2 type. The time was 5 minutes from the starting extract preparation until the optical measurement of solutions' density.

The experiments were carried out within 10-30 minutes, in 3 repetitions. The results were statistically processed, an error did not exceed 5\% [Плохинский, 1970].

\section{Received results and their discussion}

According to the results, from the influence of salt $(0.05$ and $0.1 \mathrm{M} \mathrm{NaCl})$, the reduction activity of 2.6DXFIF was lower than the control system. It can be seen from the curves for light indicator $(\mathrm{T})$ of filtrate as a result of the change in colour related to the reduction of 2.6-DXFIF (figs. 1, 2, 3, 4).

It should be noted that on seeds soaked in a solution of $0.2 \mathrm{M} \mathrm{NaCl}$, it was not possible to determine the reduction activity of seedlings since it had a very small percentage of germination.

According to the curves obtained from the wheat sprouts on low concentrations of $\mathrm{NaCl}(0.05 \mathrm{M})$ in the root system, the value of $\mathrm{T}$ was the same as the control system until saturation occurs; and close to it in the trunk, in the version of the experiment $0.1 \mathrm{M}$ has been down the control system in both cases. After 10 minutes from the beginning of the experiment T's value has increased linear in all variants; stabilization for the root in control system was the 50th, in experiment variants $(0.05$ and $0.1 \mathrm{M})$ was the 30 th, and in root in control was 40 th, on $0.05 \mathrm{M}$ was 30 th and on $0.1 \mathrm{M}$ occured on 40 th minute (figs. $1 \mathrm{a} ; 1 \mathrm{~b}$ ).
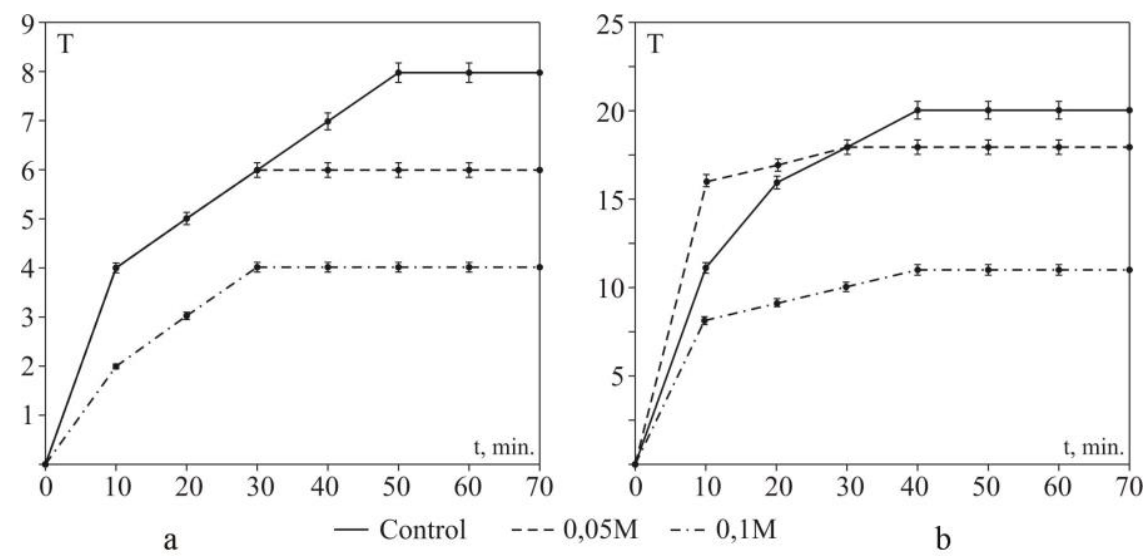

Figure 1. Reduction of 2.6-DXFIF on wheat seedlings' roots (a) and trunk (b) etiolated for 7 days grown in water and $0.05 \mathrm{M}$ and $0.1 \mathrm{M}$ concentration solutions of $\mathrm{NaCl}$ for light indicator

Reduction activity in the root system of etiolated pea sprouts were relatively close to the control on low concentration as on wheat sprouts, however, on high concentration was lower than that. (fig. 2a). This similarity has not been identified in the trunk, so that the results in both concentrations decreased compared to the control (fig. 2b). The stabilization of reduction of 2.6-DXFIF for root in all cases was 40, in trunk on control was 50 , in experiment options was observed after 40 minutes. 

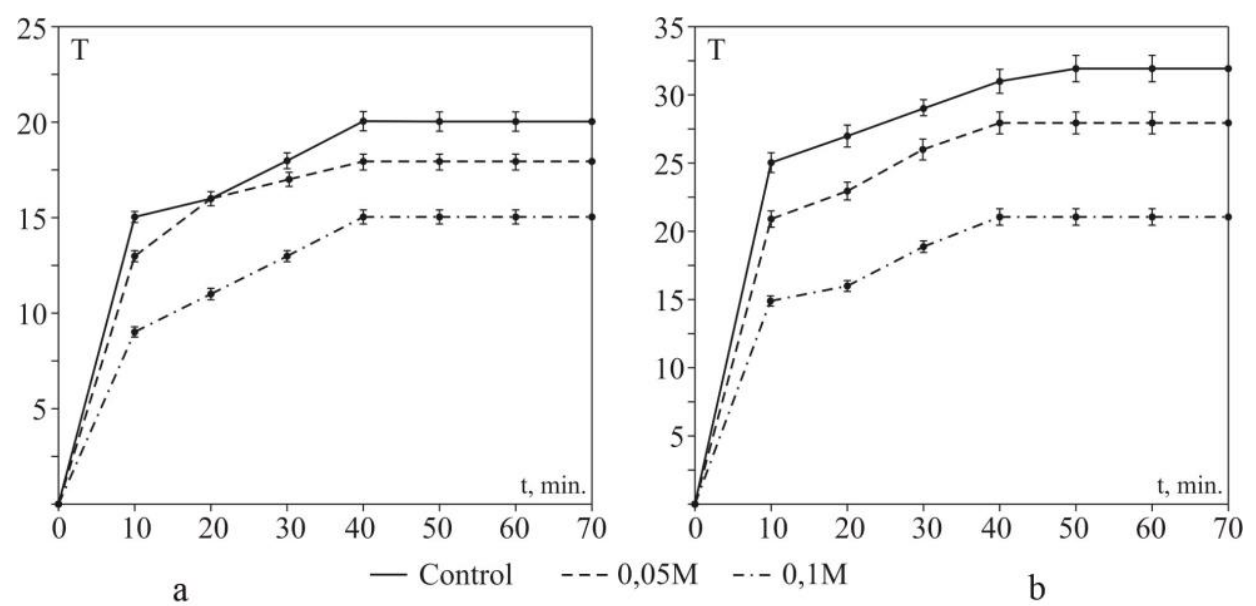

Figure 2. Reduction of 2.6-DXFIF on pea seedlings' roots (a) and trunk (b) etiolated for 7 days grown in water and $0.05 \mathrm{M}$ and $0.1 \mathrm{M}$ concentration solutions of $\mathrm{NaCl}$

So, in the root and trunk of etiolated seedlings, stages comes from reduction curves of 2.6-DXFIF. Such stages are adequate in control and salt options: reduction of colouring firstly grows linear, then reaches the maximum level and stops completely. It should be noted that maximum reduction of colouring in control for the root system ends in 40th-50th minutes, but for the experiment options this period was equal to 30-40 minutes. As it can be seen, root system's reduction capacity is significantly reduced under the influence of salt.

A decrease in reduction capacity under the effect of salt can be seen more clearly from the obtained curves for the trunk. So that, the first phase for reduction curves of colouring for wheat on control was 16 ; on $0.05 \mathrm{M}$ concentration solution of $\mathrm{NaCl}$ was 11 ; on $0.1 \mathrm{M}$ was 8 , respectively for the peas it was equal to $25 ; 21$ and 15 . (figs. $1 \mathrm{~b}, 2 \mathrm{~b}$ ). It shows the amount of reduction components in homogenate decreased nearly twice under the effect of salt; and oxidation activity increased. The received regularity adequately was found on the root and trunk of monocotyledonous and dicotyledonous plants. This regularity can be associated with oxidation activity of salt solutions, in particular, $\mathrm{Cl}^{-}$anions. Thus, according to the literature data, it is the second element and the seventh group of the periodic system, is known as $\mathrm{Cl}^{-}$oxidant stands in the second place after Fluor according to the electro-negativity; and the existance of this ion (as well as other ions) on the environment causes oxidation reactions go faster [Abduyeva-Ismailova et all., 2013] (fig. 3).

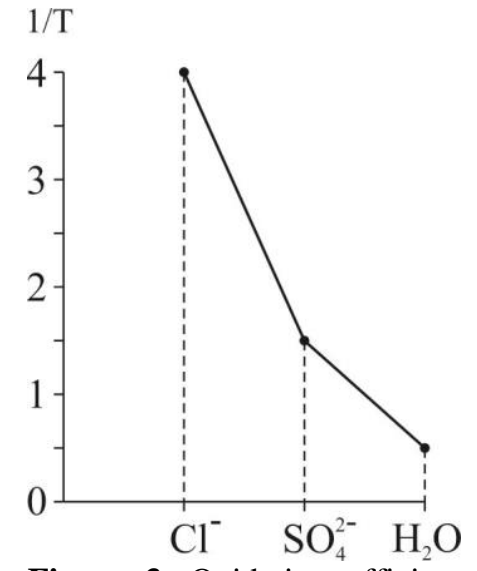

Figure 3. Oxidation efficiency $\left(\mathrm{Na}_{2} \mathrm{SO}_{3}+1 / 2 \mathrm{O}_{2}--\right.$ $\mathrm{Na}_{2} \mathrm{SO}_{4}$ ) of $\mathrm{Cl}^{-}$və $\mathrm{SO}_{4}{ }^{2-}$ ions on $\mathrm{Na}_{2} \mathrm{SO}_{3}$. Inverse value of $\mathrm{Na}_{2} \mathrm{SO}_{3}$ with $\mathrm{ml}$ until a complete waste dissolved oxygen in them to $1 / \mathrm{T}-30 \mathrm{ml}$ distillation water and salt solutions

In the next experiments, the etiolated seedlings, grown in water, were subject to instant influence of salt during the definition of the reduction activity. A wide spectrum for concentration of salt solution can be used during such a direct salinization, by adding to homogenate. So that, experiments carried out by an instant salinization is used while impossibility of reduction activity determination due to the bad grow of seeds soaked in $0.2 \mathrm{M}$ considered as stress concentration of salt solution.

In homogenate of wheat seedlings' root and trunk, directly affected by salt reduction activity in low concentrations $(0.05 \mathrm{M}$ and $0.1 \mathrm{M})$, is higher than control, but on $0.2 \mathrm{M}$ concentration was lower than this (fig. 4). Saturation for control on root was equal to 8 at the 50th minute, but in all the experiment options it was equal to $13(0.05 \mathrm{M})$ starting from the 30 th minute; it was equal to 8 at $(0.1 \mathrm{M})$ and to 5 at $(0.2 \mathrm{M})$. 
Saturation for trunk was after 40-50 minutes, and results were high for the root: it was 20 on control, 24

at $0.05 \mathrm{M} ; 23$ at $0.1 \mathrm{M}$ and 13 at $0.2 \mathrm{M}$.
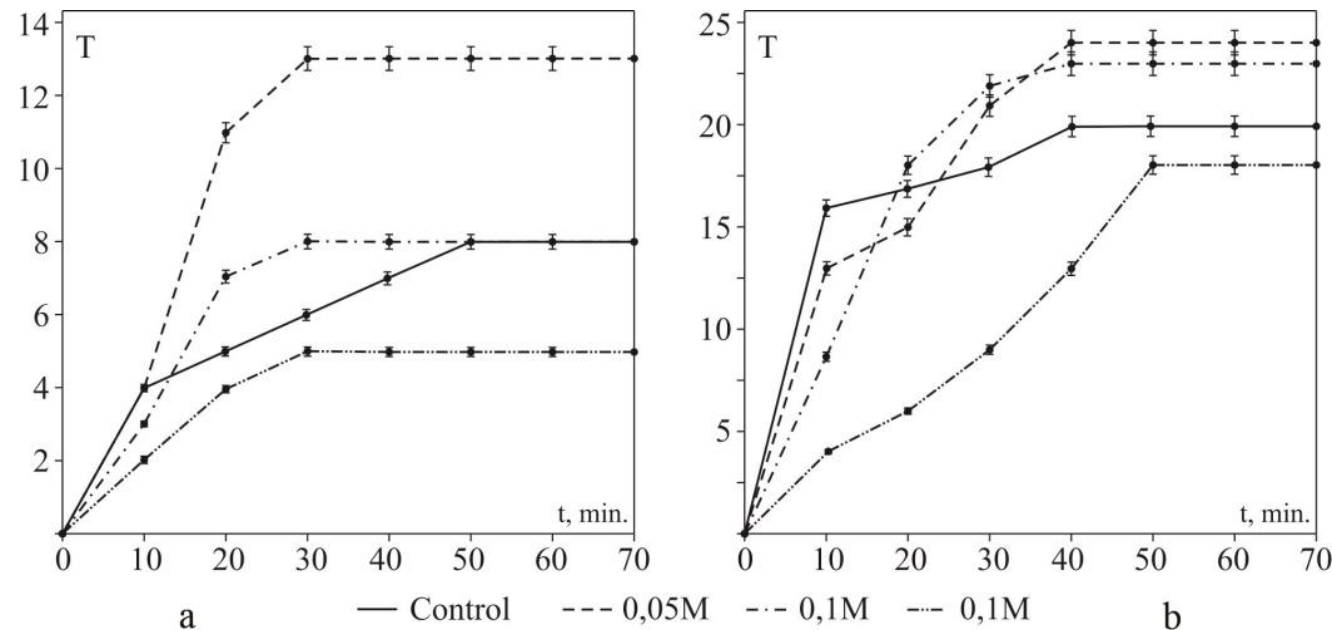

Figure 4. 2.6-DXFIF reduction on wheat seedlings' root (a) and trunk (b) have been instantly affected by salt stress

Reduction activity of pea sprouts have been instantly affected by salt stress decreased compared to control (fig. 5). As in the seedlings kept in salt solutions, in these experiments the results did not differ from each other sharply until the control occurs in root and the saturation in $0.05 \mathrm{M}$ experiment option. However, it was lower than this in high concentration $(0.1 \mathrm{M}$ and $0.2 \mathrm{M}$ ) (fig. 5a). The results have fallen sharply compared to the control system in all concentrations of homogenate made from trunk of sprouts (fig. 5b).
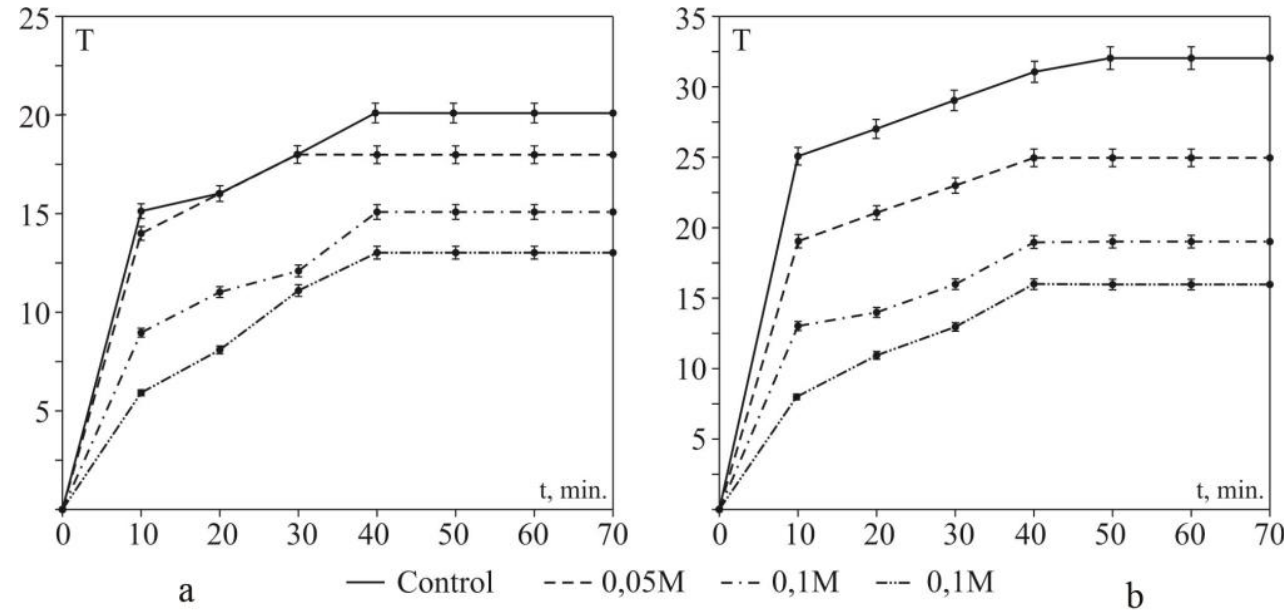

Figure 5. 2.6-DXFIF reduction on pea seedlings' root (a) and trunk (b) have been instantly affected by salt stress

The stabilization of reduction of 2.6 DXFIF for root occured after 30th minute on 0.05 option, on control and the all remaining options after 40th, for trunk it occured after 50th, on experiment options after the 40th minute.

It should be noted that the reduction activity on trunk was higher compared to the root system of the seedlings that left in salt solutions and have been exposed to direct salt stress. The reason for this can be direct and everyday contact of the root system with the salt.

The figure is higher in the second case, if we compare the reduction potential in etiolated wheat and pea seedlings. Compared to wheat, the reduction activity in pea sprouts was higher in the roots about 3 times, and on trunk about 1.5 times. The bigger size of pea seeds and existence of reserve item - protein that had been much more reduced can be reasons for that.

So, according to the results received from the experiments, reduction activity's changing nature is almost similar on root and trunk of seedlings that left in salt solutions and have been exposed to direct salt stress; the increasing concentration of salt solution causes linear decrease of reduction activity. 2.6- 
DXFIF passes to completely reduction conditions after 30-40 minutes on filtrate emerged from the seedlings under the effect of salt. It shows the accelerated respiration and rapid pass of all components of the respiratory system to the oxidized situation within the prescribed period under the effect of salt on roots and trunks. In this respect, the reduction activity on seedlings decreases. The experiments were carried out in order to determine the changes for the reduction potential of the root system and the amount of photosynthetic pigments under the effect of salt in natural lighting conditions on 7-days sprouted seedlings, taking into account that the reduction activity changes depending on the photosynthetic activity of seedlings.

In a very short time, within a few seconds forerunners like protochlorophyllides, chlorophyllides of chlorophyll are accumulated while lightining the etiolated seedlings. The formation of its forerunners occurs very fast, since it is photochemical process and it is impossible to determine them visually. Therefore, the total amount of photosynthesized pigments on seedlings has been defined in experiments with photometric method.

As it is known, donor-acceptor relations among the roots and trunks of plants are not unilateral, but bilateral and these relationships can change on ontogenesis. Root integrates to donor, autotroph before the germination of seeds, formation and flowering of overhead unit, and trunk integrates to donor after nutrition and at the same time root

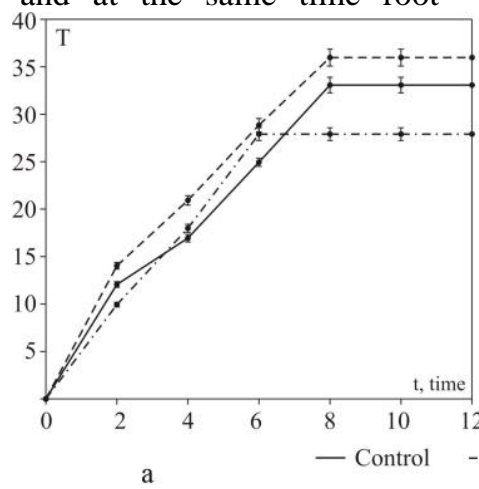

integrates to acceptor. The main goal of the research work is the definition of the changes of donoracceptor relations among the trunk and root systems with the accumulation of photosynthetic pigments in salty conditions.

The received results show that continuous lighting for 6-8 hours allows accumulation of enough photosynthetic pigments. The lightening index for homogenates made of green wheat and peas seedlings in control and the whole experiment options had linear increase, and after 6-8 hours the saturation has occurred. In other words, an increase in the amount of pigments in any case was characterized by similar curve, and the only difference was quantitative.

Control in wheat seedlings and and accumulation level of photosynthesized pigments on $0.05 \mathrm{M}$ salt option reaches a maximum within 8 hours. This indicator was 33 with the relative numbers on control, reached 36 on $0.05 \mathrm{NaCl}$, and when the salt concentration was $0.1 \mathrm{M}$ it was equal to 28 within 6 hours. In other words, a low concentration of salt solution presenting stimulating effect accelerates the synthesis of pigments, saturation state of high concentration (8 hours) compared to control occurs more often (6 hours) (fig. 6a).

According to the donor-acceptor relations, the amount of the reduced items moved from leaves to roots had linear increase within 6-8 hours and reached maximum (fig. $6 \mathrm{~b}$ ).

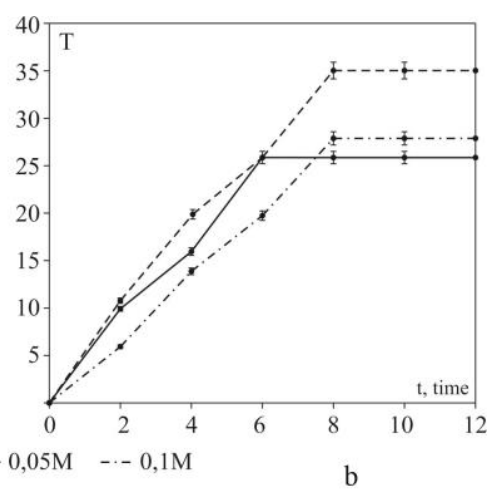

Figure 6. The amount of chlorophyll (a) and reduction potential of root system (b) in 7-days green wheat sprouts

This kind of regularity has been defined on pea seedlings as well. In all the experiments, the amount of pigments and reduction potential of root were low compared to control in pea sprouts. In all versions, both the amount of the pigments and reduction potential of the root had linear increase within 8 hours, only after the saturation occured (fig. 7). 

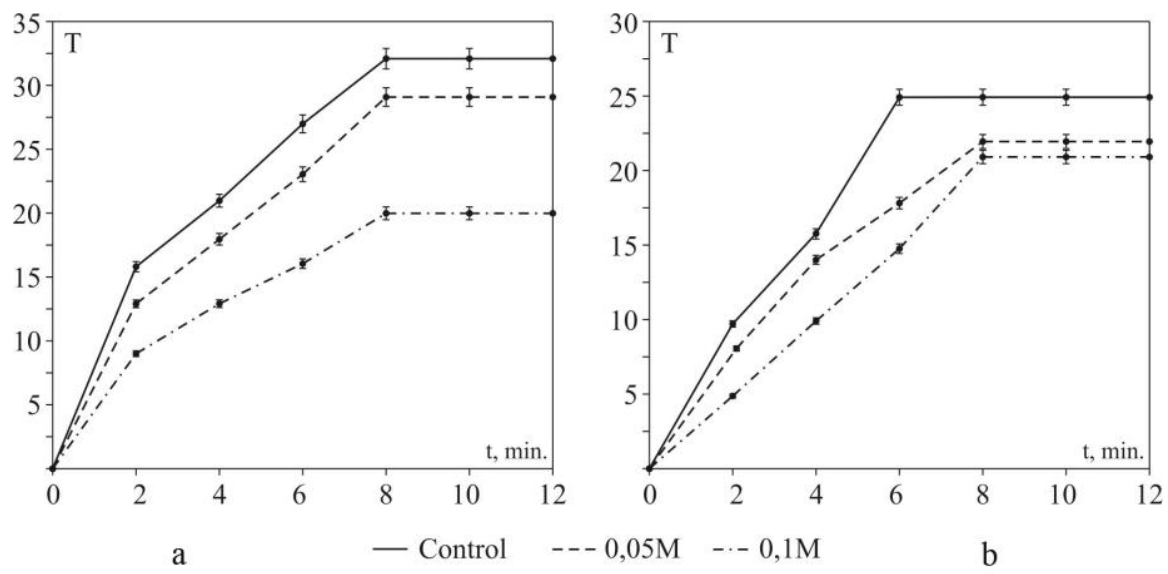

Figure 7. The amount of chlorophyll (a) and reduction potential of root system (b) in 7-days green pea sprouts

So, the increase in the amount of photosynthetic pigments on overhead units of sprouted seedlings causes to significant increase of reduction activity and acceleration of the biochemical and physiological processes along with an increase in the amount assimilations moved to the root system. It also is known from literature that the increase of reduction ability on root system allows faster absorption of chlorine ions, also an increase in its transport function. Thus, it was determined in the water culture surveys that there is a positive correlative relationship between the reduction ability of root system and absorption of $\mathrm{Cl}^{-}$ions [Gasimov, 2008].

In researches of the 1940-50s conducted by Abutalibov [Абуталыбов, 1940] in Azerbaijan and Novikov (Новиков, 1949) in Russia, has been identified that the salt resistance of crops planted in light is much lower than the plants growing in the shade. The authors could not explain this fact properly, connected its reason with "light factor" and with this they were not able to reveal the mechanism of the case.

But in the later research studies [Касумов, 1983], as well as according to the results received from our experiments, low salt resistance of plants growing in lighted areas can be explained with their more intensive process of photosynthesis. That's to say, photosynthesis in plants in the lighted-areas and consequently, the synthesis of the reduction compounds and their integration speed to the root are higher compared to plants in the shade. It causes reduction potential on roots and as a result, an increase in functional activity. And the increase of the functional activity means the absorption acceleration of all physiological processes including acceleration of absorption of ions. Consequently, such plants are more exposed to negative influence of salt. Therefore, salt resistance of these plants is low. Literature materials also confirm the unresitance for external environment factors of the organisms that have an intensive metabolic processes and the high level of sustainability for the organisms that have a weak metabolism process [Abduyeva, 2003].

We come to this conclusion based on the results that the salt resistance of plants is not genetic process, it is the process regulated on metabolic level. Oxidation activity of plants can be enhanced to boost salt resistance of plants. It is not accidental that the oxidation activity in halophytes in nature is high [Кузнецов, 2006].

\section{BIBLIOGRAPHY}

1. Abduyeva S.M. (2003) Study of oxidative and antioxidant activity of plants in saline conditions// Dissertation thesis. Baku, p. 149 p.

2. Abduyeva-Ismailova S.M., Gasimov N.A. (2013) Salt stress at plants and its investigation methods// American Journal of Research Communication, 2013, 1(8): 1-7.

3. Gasimov N.A. Plant Physiology. Baku: Baku State University press, 2008, pp. 484.

4. Абуталыбов М.Г. (1940) Влияние хлоридов на хлопчатник в различных фазах развития. Тр. Бот. инта Азерб. Фил АН СССР, т.ІХ, Баку, стр.58-70.

5. Касумов Н.А., Тагизаде А.Х. (1976) Методы оценки устойчивости растений к неблагоприятным условиям среды. Ленинград, Колос, стр.266-271.

6. Касумов Н.А. (1983) Физиолого-биофизические аспекты механизма действия солей на растительный организм. Баку, Элм, стр.143.

7. Касумов Н.А.(2012) Механизм действия солей на растительный организм. ФРГ, 175 стр.

8. Кузнецов В.В., Дмитреева Г.А. (2006) Физиология растений / Москва. Высшая школа, 472 стр.

9. Новиков В.А. (1949) Влияние интенсивности света на солеустойчивость хлопчатника / В сб. «Памяти акад.А.А.Рихтера» Тр. Ин-иа Физиологии растений им.К.А.Тимирязева АН СССР, т.6, вып.2.194-198.

10. Плохинский Н.А. (1970) Математический методы в биологии. М.Наука. 